\title{
Penerapan Komunikasi Interpersonal dalam Kajian Islam pada Penyiar Ajang Duet Radio Dhirgantara Best Station 101,9FM Banjarmasin
}

\author{
Nor Yulia Syifa, Shanty Komalasari, dan Musfichin \\ Universitas Islam Negeri Antasari Banjarmasin
}

\begin{abstract}
This research has main objectives is to identification what broadcast programs apply interpersonal communication in Islamic studies by duet broadcasters, to description how the application of interpersonal communication in Islamic studies to duet broadcasters. Than, to find out what factors influence the application of interpersonal communication in Islamic studies to duet broadcasters at Radio Dhirgantara Best Station 101.9FM Banjarmasin. This study used descriptive qualitative research methods with interview, observation and documentation data collection techniques. The results show that there are 2 duet events that apply interpersonal communication in Islamic studies, namely dBs Most Popular \& dBs Popcorn. In the use of interpersonal communication, it was found that the subject applied Qaulan Sadidan, Qaulan Maysura, Qaulan Layyinan, Qaulan Kariman, Qaulan Ma'rufan, and Qaulan Baligha with some notes. The most influencing factors for this use are factors that come from external subjects, namely the environment around the subject which is influenced by the subject, besides that the research subjects feel that when applying some aspects they can get or feel pleasure in themselves.
\end{abstract}

Keywords: interpersonal communication; islamic studies; announcer; psychology; radio.

\begin{abstract}
Abstrak
Penelitian ini memiliki tujuan untuk mengidentifikasi program siaran apa saja yang menerapkan komunikasi interpersonal dalam kajian Islam oleh penyiar ajang duet, mendeskripsikan gambaran penerapan komunikasi interpersonal dalam kajian Islam pada penyiar ajang duet tersebut. Serta, mengetahui faktor-faktor apa saja yang mempengaruhi terjadinya penerapan komunikasi interpersonal dalam kajian Islam pada penyiar ajang duet di Radio Dhirgantara Best Station 101,9FM Banjarmasin. Penelitian ini menggunakan metode penelitian kualitatif deskriptif dengan teknik pengumpulan data wawancara, observasi dan dokumentasi. Hasil menunjukan bahwa terdapat 2 ajang duet yang menerapkan komunikasi interpersonal dalam kajian Islam, yaitu dBs Most Popular \& dBs Popcorn. Dalam penerapan komunikasi interpersonal ditemukan bahwa subjek menerapkan Qaulan Sadidan, Qaulan Maysura, Qaulan Layyinan, Qaulan Kariman, Qaulan Ma'rufan, dan Qaulan Baligha dengan beberapa catatan. Faktor yang paling banyak mempengaruhi penerapan tersebut adalah faktor yang datang dari luar diri subjek yaitu lingkungan sekitar subjek yang membiasakan subjek menerapkan aspek-aspek tersebut, selain itu juga subjeksubjek penelitian merasa ketika menerapkan beberapa aspek mereka bisa mendapatkan atau merasakan rasa senang dalam diri mereka masing-masing.
\end{abstract}

Kata kunci: komunikasi interpersonal; kajian islam; penyiar; psikologi; radio. 
Tujuan komunikasi interpersonal adalah agar individu dapat lebih memahami diri sendiri dan orang lain, sehingga mengarah pada dan memelihara hubungan interpersonal yang baik, yang dapat mempengaruhi sikap dan perilaku, menjadi media atau penghubung bagi orang untuk saling membantu. Beberapa hal yang menjadi tujuan komunikasi interpersonal menjadi penting, karena sebagai individu sosialisasi harus menjalin dan menjaga hubungan baik dengan orang lain, karena manusia harus mampu melakukan komunikasi interpersonal yang baik untuk mencapai tujuan tersebut. Demikian pula jika seseorang ingin dapat mengubah perilaku dan sikap orang lain, hal ini dapat disertai dengan upaya persuasif melalui komunikasi interpersonal.

Perspektif sosial budaya merupakan faktor utama yang mempengaruhi terciptanya komunikasi yang efektif. Mematuhi perspektif sosial dan budaya dalam komunikasi interpersonal, artinya jika disusun dari perspektif budaya dan sesuai dengan kaidah-kaidah komunikasi, maka komunikasi antarpribadi akan berjalan dengan baik. Aturan ini adalah bahwa setiap orang memiliki keadilan dalam komunikasi. Jika ada konflik dengan proses dan orang lain, harus ada toleransi dalam setiap komunikasi. Tentu setiap orang memiliki pandangan yang berbeda. Inilah sebabnya mengapa kita harus memahami penyebaran dalam studi Islam secara lebih luas. Karena ditegaskan pula bahwa pengertian komunikasi dalam ajaran Islam adalah cara menyampaikan informasi dengan nilai-nilai agama Islam. Sehingga dapat dipahami bahwa nilai-nilai yang diajarkan Islam memang harus diterapkan dalam komunikasi interpersonal (Na'imah dan Septiningsih, 2019).

Aspek-aspek komunikasi interpersonal dalam studi Islam adalah:

Qaulan Sadīdan. Ketika berkomunikasi menyampaikan informasi harus didasari dengan fakta dan data dari sumber yang benar dan jelas tanpa ada kebohongan di dalamnya. Bersumber dari Q.S. An-Nisa/4: 9 (Alquran, 2010)

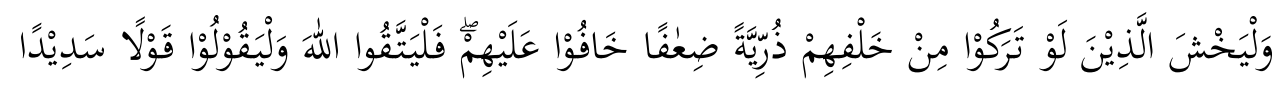

"Dan hendaklah takut kepada Allah orang-orang yang mereka meninggalkan keturunan yang lemah, yang mereka khawatirkan (kesejahteraannya). Karena itu, izinkan mereka bertakwa kepada Allah dan hendaklah mereka mengucapkan perkataan yang benar."

Qaulan Maysura. Saat berkomunikasi harus memperhatikan cara penyampaianya. Dalam islam dalam menyampaikan informasi harus dengan kalimat yang menyenangkan 
lawan bicara dan memberikan kesan optimisme terhadap lawan bicaranya. Bersumber dari Q.S. Al Isro/17: 28

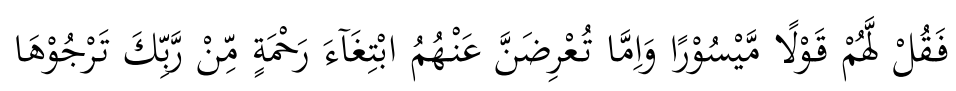

"Dan jika kamu berpaling dari mereka untuk mendapatkan rahmat dari Tuhanmu yang hanya kamu harapkan, maka beri tahu mereka dengan kata-kata yang pantas."

Qaulan Layyinan. Diusahakan saat berkomunikasi harus dengan lemah lembut, mengajak ke hal baik, meyakinkan. Bersumber dari Q.S. Thoha/20: 44.

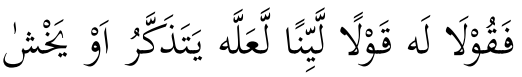

"Maka berbicaralah kamu berdua kepadanya dengan kata-kata yang lemah lembut, mudahmudahan ia ingat atau takut."

Qaulan Kariman. Komunikator harus berkata santun, tanpa kalimat yang kasar. Bersumber dari Q.S. Al Isra/17: 23.

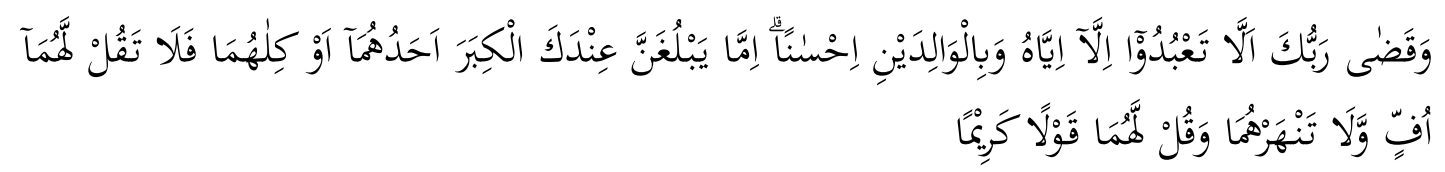

"Dan Tuhanmu telah menyuruhmu untuk tidak menyembah selain dari-Nya dan berbuat baik kepada ibu dan bapak dengan sebaik-baiknya. Jika salah satu dari mereka atau masingmasing dari mereka sampai berumur lanjut dalam pemeliharaanmu, maka jangan sekali-kali kamu mengatakan kepada mereka perkataan "ah" dan janganlah kamu membentak, dan ucapkanlah kepada mereka perkataan yang mulia."

Qaulan Ma'rufan. Ketika berkomunikasi dianjurkan untuk menggunakan kalimat yang bijak tanpa menyinggung perasaan orang yang menjadi lawan bicaranya. Bersumber dari Q.S. An-Nisa/4: 8.

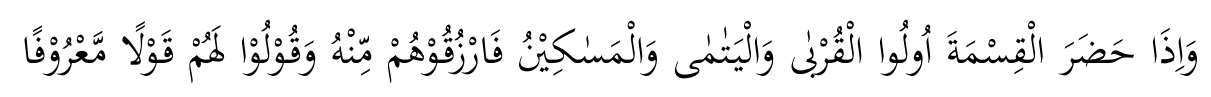

"Dan jika sewaktu-waktu ada sanak saudara, anak-anak yatim, dan orang-orang miskin, maka berilah mereka harta (semata-mata) dan ucapkanlah kepada mereka perkataan yang baik."

Qaulan Baligha. Saat berkomunikasi dianjurkan untuk menggunakan kalimat dan Bahasa yang mudah dipahami. Bersumber dari Q.S An-Nisa/4: 63.

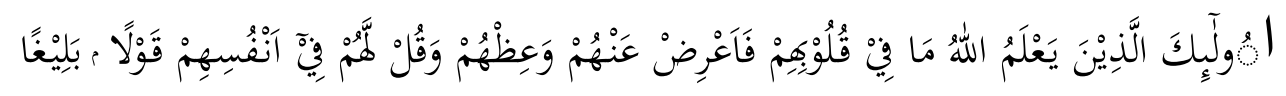


"Mereka adalah orang-orang yang sesungguhnya Allah mengetahui apa yang ada di dalam hati mereka. Maka, berpalinglah kamu dari mereka, berilah mereka nasihat, dan katakanlah kepada mereka perkataan yang jelas membekas pada jiwanya."

Komunikasi interpersonal pada kajian Islam adalah suatu komunikasi yang penting keberadaannya untuk individu yang beragama Islam karena, pesatnya perkembangan teknologi menjadi permasalahan utama dalam komunikasi (Riady dan Hum 2010). Perkembangan teknologi sebenarnya memberikan dampak yang postif tetapi juga ada dampak negatif yang ditimbulkan. Dampak positifnya adalah, teknologi informasi memungkinkan kemudahan dalam menyampaikan informasi dengan luas. Sedangkan dampak negatifnya manusia menjadi ketergantungan dengan teknologi. Secara tidak sadar teknologi sudah mendampingi hidup manusia saat ini dalam berkomunikasi. Sistem penyampaian informasi semacam itu berkaitan dengan salah satu alat penyampaian informasi yang luas yaitu media masa.

Salah satu media masa yang digunakan sebagai penyampai informasi dan hiburan untuk masyarakat dengan menggunakan teknologi dan pesan suara adalah radio. Radio merupakan media masa yang masih unggul menjadi media informasi bagi masyarakat sebagai sarana informasi dan hiburan. Di samping itu, radio merupakan media yang mempunyai karakteristik akrab dengan orang yang mengaksesnya, sehingga membuat informasi yang disampaiakan kepada pendengar dapat lebih spesifik juga lebih jelas untuk memahami maksud dan tujuannya (Trinoviana 2017).

Sebagai sarana komunikasi, radio adalah salah satu media siaran elektronik guna menjangkau banyak pendengar atau masyarakat umum. Salah satu media komunikasi yang dapat menjangkau setiap kelompok. Berdasarkan fakta, hingga tahun 1994 tercatat ada tiga puluh empat juta stasiun radio di Indonesia yang dilayani oleh empat puluh sembilan stasiun radio pemerintah (RRI), 670 stasiun radio pribadi bisnis dan 133 stasiun radio pemerintah atau lengkap 852 unit (Triartanto A.Ius.Y 2010). Pada 1975, hanya terdapat 512 stasiun radio. Hal ini menunjukkan bahwasannya radio masih dipelihara keberadaanya oleh masyarakat Indonesia.

Seseorang yang lebih suka bekerja sebagai penyiar di sebuah stasiun harus bisa mengkomunikasikan ide, konsep, dan emosi mereka, lalu bertanggung jawab dalam melakukan siaran program stasiun radio. Pekerjaan tersebut dapat berupa profesi yang menghibur khalayak dengan media radio yang disiarkannya (Wanda Yulia 2010). Secara 
profesional, penyiar belajar untuk mampu beradaptasi, berpikir dengan cepat, vokal penyiar juga unggul, dan penyiar harus memiliki keterampilan penguasaan juga pengalaman dalam mengolah kata-kata setelah siaran sehingga akan ditangkap, dimengerti, dan mudah diakses oleh pendengar agar menghindari persepsi pengetahuan. Komunikasi yang baik sedini mungkin akan membantu para penyiar dalam menjalankan tugasnya (dBs FM, 2020).

Begitu pula pada Radio Dhirgantara Best Station 101,9FM Banjarmasin, salah satu radio di Banjarmasin yang tetap eksis sampai sekarang ini walaupun berbagai media lainnya yang mulai bermunculan, merupakan radio yang berada di frekuensi FM (frequency modulation) 101,90 MHz, berdiri sejak tahun 1989, memiliki fokus pendengar 75\% untuk anak muda peneliti tertarik melakukan penelitian di radio ini. dBs FM juga menuntut penyiar untuk berkomunikasi dengan baik terhadap pendengar, rekan kerja serta atasannya. Sehingga dapat dipahami, ketika penyiar harus menjalankan ajang duet dan siaran bersama dengan partner ada keharusan untuk membangun empati hal itu bisa dimulai melalui komunikasi interpersonal yang baik dan benar bertujuan dalam menciptakan chemistry serta hubungan yang kuat antara penyiar dan partner siarannya (Y. Bambang Triyono 2017).

Lalu, menurut penuturan salah satu penyiar Muslim dari radio dBs FM yang menjalankan program duet siaran bersama partner, menyetujui keharusan terbangunnya chemistry yang diawali dengan komunikasi interpersonal antar penyiar yang baik, namun dia mengaku tidak menyadari bahwa selama ini di dalam kajian Islam ternyata ada dipaparkan aspek-aspek yang bisa membantu individu menciptakan komunikasi interpersonal yang baik, Dia merasa takjub dan menyadari bahwa hal itu harus diterapkan secara maksimal untuk menunjang profesi penyiar khususnya penyiar ajang duet.

Maka, penelitian ini memiliki tujuan untuk mengetahui bagaimana penerapan komunikasi interpersonal dalam kajian Islam pada penyiar ajang duet, mengetahui program siaran apa saja yang menerapkan komunikasi interpersonal dalam kajian Islam oleh penyiar ajang duet, dan mengetahui faktor-faktor apa saja yang mempengaruhi terjadinya penerapan komunikasi interpersonal dalam kajian Islam pada penyiar ajang duet di Radio Dhirgantara Best Station 101,9FM Banjarmasin.

\section{Metode}

Dalam menganalisa data, penelitian ini menggunakan pendekatan penelitian kualitatif dengan metode analisis kualitatif deskriptif. Analisis kualitatif deskriptif 
digunakan untuk melihat kondisi objek ataupun subjek, karena tidak mencari hubungan, tidak memeriksa hipotesis, atau membangun prediksi (Semiawan 2010).

Subjek dalam penelitian ini adalah 4 orang penyiar ajang duet, dan 1 significant others yaiut orang yang merupakan ketua divisi program \& penyiaran di Radio Dhirgantara Best Station 101,9FM Banjarmasin,. Lalu objek pada penelitian ini adalah penerapan komunikasi interpersonal dalam kajian Islam meliputi teori yang ditulis oleh Jalaluddin Rakhmat yang memiliki 6 aspek dan sudah dijelaskan sebelumnya. Dalam mengumpulkan data, peneliti menggunakan beberapa instrument yaitu wawancara, observasi dan dokumentasi.

Sedangkan untuk tahap analisis data, peneliti menggunakan tahapan collection, data reduction, data display, dan conclusion verification (Sugiyono 2020). Dengan melaksanakan proses-proses tersebut, peneliti dapat mencapai tujuan dari penelitian ini.

\section{$\mathrm{H}$ a $\mathrm{s}$ i 1}

Hasil akan membahas mengenai hasil penelitian yaitu pertama, program siaran apa saja yang menerapkan komunikasi interpersonal dalam kajian Islam oleh penyiar ajang duet. Kedua, gambaran penerapan komunikasi interpersonal dalam kajian Islam pada penyiar ajang duet. Ketiga, mengetahui faktor-faktor apa saja yang mempengaruhi terjadinya penerapan komunikasi interpersonal dalam kajian Islam pada penyiar ajang duet Radio Dhirgantara Best Station 101,9FM Banjarmasin. Peneliti menyajikan data dari perwakilan subjek saja untuk disajikan dalam jurnal ini:

Aspek Qaulan Sadidan (Berucap yang Benar)

Hasil wawancara subjek untuk aspek Qaulan Sadidan, yaitu subjek ketika siaran ajang duet dBs Most Popular terbiasa menerapkan berbicara dengan jujur, sesuai fakta, dan tidak menyebar kebohongan. Berikut kutipan wawancaranya:

"Eeee.. Harus sih ya, kalau misal dalam konteks duet dan pada saat siaran, iya." (CH: B37B50)

"Biasanya kalau misalkan saat duet karena kita memang bener-bener ngasih info jadi dicari tau dulu faktanya." (CH: B110-B119)

"Gak boleh yaa, walaupun gak siaran emang gak boleh sebenernya. Tidak boleh." (CH: B57B64)

Subjek menyetujui bahwa harus jujur saat siaran duet, saat siaran duet maka penyiar diharuskan mencari informasi yang sesuai fakta lalu baru bisa diberikan ke pendengar 
maupun ke sesama penyiar saat siaran, subjek melarang untuk berkata bohong ketika siaran duet maupun ketika tidak siaran juga sama tidak boleh berbohong.

Aspek Qaulan Maysura (Berucap yang Layak)

Hasil wawancara subjek $\mathrm{CH}$ pada aspek Qaulan Maysura yaitu, subjek mengakui bahwa saat siaran menerapkan untuk bisa berkata-kata yang sopan, tidak menghina pasangan siaran duet, dan subjek juga menyetujui bahwa sebagai penyiar harus bisa memotivasi pasangan siaran ketika moodnya sedang turun sehingga bisa naik lagi dan siaran duetnya jadi menyenangkan. Berikut kutipan wawancaranya:

"Sopan sih, sopan." (CH: B65-B78)

"Enggak, kalau secara sadar enggak.. mungkin, kalau secara tidak sadar mungkin ada.. tapi sepertinya tidak juga sih." (CH: B79-B88)

"Perlu sih, kalau misalnya memang saat itu mungkin dia lagi.. untuk menaikkan mood ya biasanya, kalau misalnya kita liat nih oh kayaknya pasangan duetnya lagi ga enak nih diajak nogbrol kayaknya bisa ditingkatkan dengan obrolan-obrolan ringan yang mungkin menarik perhatian dia, atau mungkin bikin moodnya naik gitu lebih seneng bisa.." (CH: B89-B109)

Subjek mengakui bahwa saat siaran subjek terbiasa untuk berbicara sopan ke pasangan siaran duet, subjek merasa tidak pernah menghina pasangan siaran duetnya secara sadar atau sengaja, namun kalau secara tidak sadar subjek terdengar ragu sehingga mengatakan mungkin ada, tetapi subjek kembali meyakinkan bahwa tidak pernah menghina orang lain selama siaran duet, subjek menyetujui bahwa penyiar harus memberikan rasa optimis khususnya ke pasangan ajang duet ketika siaran, dengan alasan agar ketika siaran mereka bisa lebih senang lagi.

Aspek Qaulan Layyinan (Berucap yang Lemah Lembut)

Hasil wawancara subjek pada aspek Qaulan Layyinan yaitu, subjek membenarkan bahwa saat siaran memang harus berkata dengan intonasi yang lemah lembut, mampu mengendalikan emosi, bisa tenang saat terjadi masalah, juga sebagai penyiar harus memiliki kemampuan untuk bisa persuasif dan negosiasi yang baik antara partner duet. Berikut kutipan wawancaranya:

"Sepertinya harus ya karena dalam konteks siaran.. Alasannya apa ya.. agak mikir ya saya hehehe Ya, bisa jadi biar tidak berantem meminimalisir kesenjangan biar tidak ada ketersinggungan dan interaksinya tetap berjalan." (CH: B110-B119)

"Kalau misalnya benar-benar ada masalah nih ya dari segi personal mungkin ya tapi pada saat siaran kita tetap harus dituntut untuk profesional jadi ya kalau di on air tetap seperti 
biasa tetap humble seperti biasa jadi kayak memang tidak ada terjadi masalah tapi bisa diselesaikan nanti di lain kesempatan mungkin.." (CH: B120-B137)

"Bergantian, biasanya kami diskusi." (CH: B138-144)

Ketika ditanya apakah penyiar harus berucap lemah lembut saat siaran, subjek menyatakan bahwa harus dengan alasan agar kedua belah pihak yang sedang siaran tidak tersinggung satu sama lain. Lalu, saat terjadi sebuah konflik atau masalah, subjek lebih memilih untuk bersikap profesional saat on air atau mengudara lalu akan menyelesaikannya secara baik-baik ketika sudah tidak siaran. Untuk kemampuan persuasif dari seorang penyiar itu harus disesuaikan dengan keadaan sehingga tidak terjadi pemaksaan untuk pemilihan materi yang akan disiarkan dan untuk subjek dia merasa biasa saja karena lebih sering bergantian untuk menentukan materi siaran.

Aspek Qaulan Kariman (Berucap yang Mulia)

Hasil wawancara subjek pada aspek Qaulan Kariman yaitu, subjek membagikan pesan dengan tujuan yang baik, subjek merasa tidak mengeluarkan perkataan bertujuan merendahkan orang lain apalagi pasangan duet saat siaran bersama, dan subjek merasa perlu untuk membahagiakan orang lain. Berikut kutipan wawancaranya:

"Kalau di ajang kita tuh ya otomatis mau ngasih tahu ke pendengar bahwa ada beberapa trending yang lagi populer nih di minggu-minggu ini, karena ajang ini cuma seminggu sekali ya jadi memang ngasih tahu tren-tren yang lagi viral aja mungkin supaya pendengar itu nggak kudet juga dan tahu nih oh ternyata lagu ini bercerita tentang ini atau mungkin penyanyinya terinspirasi dari ini gitu jadi bukan cuma sekedar tahu lagunya aja.. jadi tahu juga nih infonya bahwa oh ternyata lagu ini diciptakan dari ini dari ini.." (CH: B145-B158)

"Nggak pernah sih sopan sopan aja.. ini nggak tahu ya emang kalau aku ya.. misalnya ngobrol sama lawan bicara apapun konteksnya kalau misalnya itu bersifat candaan ya aku memang anggapnya candaan aja gitu nggak pernah masuk ke hati nggak pernah merasa direndahkan juga." (CH: B159-B168)

"Perkataan seperti apa ya hahaha kalimat motivasi mungkin yaa bisa bikin orang bahagia. Karena motivasi ini kan bisa membuat orang lebih semangat, yang tadinya kurang semangat jadi bertambah sehingga mungkin bisa menambah rasa bahagia orang lain juga sepertinya." (CH: B169-B193)

Subjek menjelaskan bahwa ajang duet yang dibawakannya memang merupakan ajang yang bertujuan membagikan pesan ataupun informasi yang baik. Subjek tidak merasa pernah merendahkan atau direndahkan oleh pasangan siaran duet. Untuk membahagiakan 
orang lain, entah itu pendengar ataupun pasangan siaran duet bagi subjek adalah dengan cara memberikan motivasi.

Aspek Qaulan Ma'rufan (Berucap yang Baik)

Hasil wawancara subjek CH pada aspek Qaulan Ma'rufan yaitu, subjek mengakui bahwa ketika siaran duet diusahakan tidak berkata kasar, tidak menyinggung perasaan, dan mengusahakan agar pembicaraannya bermanfaat. Berikut kutipan wawancaranya:

“Nggak nggak pernah sih kalau secara sadar emang enggak pernah. Karena kita udah punya apa ya kalau di siaran itu ada batasan atau etika ya.. ada etika dasarnya ketika ngobrol di jam on air itu emang nggak diperbolehkan memakai kata ini, atau kata ini, jadi itu udah jadi ingatan tersendiri aja nggak boleh ngomong beberapa kata yang tergolong kasar yang nggak boleh disebutin sama penyiar seperti kata-kata sumpah serapah atau mungkin kata-kata cacimaki Nah itu merupakan kata-kata yang dilarang diucapkan sama penyiar" (CH: B194-B206)

"Perlu. Alasannya karena kalau misalnya tadi ada tersinggung otomatis terjadi kesenjangan komunikasi antara penyiar dan membuat ngobrolnya jadi nggak enak, jadinya canggung dan itu jadi tujuannya memang biar ga tersinggung satu sama lain." (CH: B207-B214)

"Iya.. jadi kalau misalnya ajang duet itu saya kebetulan di dBs Most Popular yah.. dan itu tuh, hari Selasa biasanya dari jam 7 malam sampai jam 10 malam.. terus lagu-lagu yang diputar itu mancanegara sama Indonesia, dan yang terbaru pastinya karena kita juga ngambilnya dari temanya mostpopular, jadi bener-bener yang kayak populer pada saat itu gitu, yang lagi digandrungin apa gitu.. Dan terus juga yang masuk tranding di youtube jadi itu yang dibahas." (CH: B8-B36)

Subjek menjelaskan bahwa ketika menjadi penyiar memang sudah diajarkan untuk tidak menyebutkan kata-kata yang kasar, hal itu membuat subjek menjadi terbiasa saat siaran duet memang tidak berkenan mengatakan kata-kata yang kasar. Subjek merasa perlu untuk menjaga perasaan partner duet dan merincikan ajang duet dBs Most Popular berisikan pembahasan bermanfaat.

Aspek Qaulan Baligha (Berucap yang Jelas)

Hasil wawancara subjek $\mathrm{CH}$ pada aspek Qaulan Baligha yaitu, subjek merasa perlu ketika siaran duet untuk berkata atau berbicara dengan makna yang jelas, mudah dimengerti, dan tepat mengungkapkan apa yang dikehendaki ke partner siaran. Berikut kutipan wawancaranya:

"Perlu, yaa biar bisa mudah dipahami." (CH: B215-B247)

"Apa ya kiat-kiat khususnya.. apa ya kayaknya em.. kiat-kiat ya.. berarti aku harus ngajarin orang gitu ya hahaha.. kayaknya eggak ada sih teknik tertentu gitu. Karena kalau misalnya ngobrol ya sejalannya aja, tapi kita juga harus tahua bahwa oh ternyata obrolon ini memang 
harus disampaikan gitu dan ada juga obrolan yang nggak perlu disampaikan jadi harus bisa baca situasi bisa pilah-pilah.." (CH: B215-B247)

"Pernah, pernah, pernah.. tapi syukurnya partnernya peka jadi dia tahu maknanya gitu apa yang mau disampaikan.. jadi dibantuin sama partner siaran dan itulah fungsinya partner siaran memperjelas apa yang kurang jelas ahahahaa" (CH: B248-B255)

Subjek menyatakan perlu untuk berkata jelas ketika siaran duet bersama pasangan. Subjek membenarkan untuk mudah dimengerti maka penyiar ajang duet harus bisa mencoba mengerti dan mencoba memilah kalimat yang akan dilontarkan disesuaikan dengan keadaan juga pembahasan saat siaran. Subjek pernah merasa kesulitan untuk menyampaikan tujuannya ke pasangan duet, namun dengan dibantu akhirnya bisa menyampaikan tujuan secara jelas sehingga mudah dimengerti oleh pasangan duet siarannya saat itu juga.

\section{Pembahasan}

Menurut Jalaluddin Rakhmat dalam buku yang beliau tulis berjudul "Islam Aktual” disebutkan bahwa, lewat komunikasi lah manusia bisa mengekpresikan dirinya kepada orang lain, bisa membantu mengembangkan kepribadian masing-masing, dan bahkan para ahli komunikasi sepakat dengan para psikolog bahwa kegagalan komunikasi bisa berakibat fatal, karena hal itu bisa menyebabkan frustasi bahkan penyakit-penyakit jiwa lainnya.

Kita sebagai makhluk sosial yang menggunakan komunikasi dalam kehidupan sehari-hari harusnya lebih memperhatikan lagi komunikasi yang kita gunakan agar tidak gagal sehingga tidak menyebabkan akibat fatal bahkan sampai menyebabkan frustasi ataupun penyakit-penyakit jiwa lainnya. Jalaluddin Rahkmat menyatakan bahwa agama Islam memberi perhatian yang serius dalam konteks berkomunikasi, beberapa ayat Alquran menjelaskan konsep-konsep penting, yang dapat dilihat sebagai bukti. yang bisa digunakan individu menjadi pedoman untuk berkomunikasi satu sama lain antar individu. Maka, Jalaluddin Rakhmat menjabarkan ada aspek-aspek komunikasi interpersonal dalam kajian Islam yaitu: qaulan sadidan (berucap yang benar), qaulan maysura (berucap yang layak), qaulan layyinan (berucap yang lemah lembut), qaulan kariman (berucap yang mulia), qaulan ma'rufan (berucap yang baik) and qaulan baligha (berucap yang jelas).

Ajang dBs Most Popular dan dBs Popcorn ini merupakan 2 ajang yang menurut peneliti memiliki atau menerapkan aspek-aspek komunikasi interpersonal dalam kajian 
Islam menurut Jalaluddin Rakhmat, karena dari hasil observasi ditemukan bahwa dari 29 ajang siaran (termasuk siaran ajang solo \& duet) ada 4 ajang duet informatif di radio Dhirgantara Best Station Banjarmasin yaitu; dBs Enjoy Corner, dBs Most Popular, dBs Showdate, dan dBs Popcorn namun menurut peneliti yang paling cocok ditelaah mendalam sesuai hasil wawancara dengan significant other adalah 2 ajang yaitu dBs Most Popular \& dBs Popcorn. Untuk menguraikan gambaran penerapan komunikasi interpersonal dalam kajian Islam beserta faktor-faktor yang mempengaruhi yang merupakan temuan peneliti saat penelitian dilangsungkan, dari keempat subjek maka peneliti akan menjabarkan hasil wawancara beserta observasi secara kesimpulan atau singkat dan jelas dari masing-masing subjek-subjek penelitian.

Pertama qaulan sadidan, berucap yang benar. Dari hasil wawancara dan observasi terhadap subjek peneliti menyimpulkan bahwa keempat subjek menerapkan aspek qaulan sadidan, karena mereka mengatakan atau membagikan informasi ke orang lain khususnya kepada pasangan siaran duetnya maupun kepada pendengar sesuai dengan informasi yang mereka dapatkan dari sumber informasi dari website di internet yang mereka cukup percayai kebenarannya, lalu mereka juga tidak menyetujui untuk berbagi hal yang tidak sesuai fakta yang terjadi atau menyebarkan kebohongan ke orang lain. Hal ini selaras dengan teori dari Jalaluddin Rakhmat yang menyatakan, komunikasi yang jujur akan menghasilkan penyampaian pesan yang tepat berdasar fakta dan data, yang mana dalam menjamin dialog yang benar diperlukan adanya nilai kejujuran, maka yang dimaksud dengan kejujuran yakni kesesuaian antara apa yang dikatakan dengan yang sebenarnya terjadi. (Jalaluddin Rakhmat 2021) Informasi yang tidak sepenuhnya diketahui sumbernya tidak boleh dikomunikasikan oleh seorang komunikator seorang komunikator.

Kedua qaulan maysura, berucap yang layak. Untuk hasil dari wawancara dan observasi dari keempat subjek ternyata ada perbedaan yaitu dalam hal penerapanya. Peneliti menyimpulkan bahwa dalam kondisi bercanda subjek tidak menerapkan aspek ini karena dalam menyampaikan suatu pesan, komunikator hendaknya memadukannya dengan kalimat yang membangkitkan semangat dan optimis terhadap lawan bicara (Djamarah 2020). Sehingga sesuai dengan data wawancara dan observasi ketika subjek 2 (NKP) berada dalam kondisi bercanda dirinya lebih sering berkomunikasi dengan kalimat yang tidak santun. 
Ketiga qaulan layyinan, berucap yang lemah lembut. Teori ini menyatakan bicaralah dengan lemah dan lembut. Memahami lawan bicara, serta dapat mengontrol emosi dengan baik, berbicara dengan lembut berdampak pada ketenangan komunikator dan dapat mengubah situasi yang terjadi. Tidak jarang, orang akan merasa terganggu jika mendengar orang lain berbicara dengan intonasi yang tinggi, apalagi jika ditambah dengan perkataan atau kata-kata yang kasar. Maka, terdapat subjek yang dinyatakan tidak menerapkan karena pembawaan dari dirinya yang tidak bisa menjadi individu yang lemah lembut.

Keempat qaulan kariman, berucap yang mulia. Berikut hasil dari wawancara juga observasi dari keempat subjek pada penelitian mengenai aspek yang satu ini. Penerapan aspek ini karena sebagai penyiar ajang duet tidak boleh merendahkan pasangan duetnya maka harus menggunakan bahasa yang santun dan subjek juga menyetujui untuk bisa menyenangkan orang lain karena menurut subjek hal itu juga membuat dirinya sennag. Selain itu, mereka merasa berucap yang tidak baik itu tidak akan mendatangkan keuntungan jadi lebih baik mereka berkomunikasi dengan cara yang membuat mereka senang. Saat berkomunikasi sebaiknya komunikator menentukan bahasa yang santun terlebih dahulu, agar komunikator dapat merasa senang, dihargai, serta dihormati oleh orang lain sesuai dengan pernyataan dari keempat subjek (Muslimah 2016).

Kelima qaulan ma'rufan, berucap yang baik. Untuk aspek ini peneliti menemukan hasil dari wawancara dan observasi subjek-subjek penelitian yaitu, penyiar yang setuju dan mengusahakan untuk menerapkan berucap yang baik, sedangkan terdapat subjek juga menyetujui untuk bisa tidak berkata kasar pada pasangan siaran duet atau bahkan orang lain namun mereka berdua mengakui ketika tidak siaran dan dalam konteks bercanda atau guyonan mereka berdua ada kemungkinan untuk berkata-kata kasar. Maksudnya adalah, ucapan yang baik adalah ucapan yang diterima sebagai sesuatu yang baik dalam pandangan banyak orang di sekitar (Na'imah dan Septiningsih 2019).

Keenam qaulan baligha, berucap yang jelas. Melihat hasil dari wawancara dan observasi untuk aspek ini peneliti menyatakan keempat subjek penelitian menerapkan aspek ini. Karena jika komunikator menggunakan bahasa yang sederhana, tepat sasaran, mudah dikomunikasikan, mudah dipahami, lugas dan tidak berbelit-belit, maka komunikasi akan terjalin dengan efektif. Kosakata yang diucapkan dapat dipahami langsung bagi komunikator, dan gaya bahasanya sesuai dengan sikap komunikator, serta 
menggunakan tata bahasa yang baik dan benar (Mubarok \& Made Dwi Andjani 2014). Dan hal-hal itulah yang dilakukan oleh keempat subjek ketika siaran duet bersama pasangan duetnya.

\section{Kesimpulan}

Berikut adalah kesimpulan yang dapat peneliti jelaskan setelah peneliti menjabarkan hasil data juga pembahasan yang telah dilakukan, yaitu terdapat 2 ajang duet yang menerapkan komunikasi interpersonal dalam kajian Islam, yaitu dBs Most Popular \& dBs Popcorn. Dari kedua ajang ini terdapat 4 subjek yang diteliti lebih mendalam seputar penerapan komunikasi interpersonal dalam kajian Islam yang dilakukan masing-masing indvidu sebagai penyiar ajang duet radio Dhirgantara Best Station Banjarmasin. Gambaran Penerapan Komunikasi Interpersonal dalam Kajian Islam pada Penyiar Ajang Duet Radio Dhirgantara Best Station Banjarmasin adalah peneliti jadi mengetahui untuk aspek qaulan sadidan keempat subjek yaitu $\mathrm{CH}, \mathrm{NKP}, \mathrm{AFH}$, dan ARN menerapkannya. Lalu untuk aspek qaulan maysura subjek $\mathrm{CH}$, AFH, dan ARN menerapkannya sedangkan subjek NKP menerapkan tetapi ketika dalam keadaan bercanda dia bisa tidak menerapkannya. Selanjutnya aspek qaulan layyinan, subjek $\mathrm{CH}, \mathrm{AFH}$, dan ARN menerapkannya namun untuk subjek NKP dia mengakui bahwa dia tidak menerapkan namun dia menyetujui seharusnya memang diterapkan untuk penyiar ajang duet. Yang berikutnya aspek qaulan kariman, keempat subjek yaitu subjek $\mathrm{CH}$, NKP, AFH, dan ARN menyatakan menerapkannya. Aspek selanjutnya yaitu aspek qaulan ma'rufan peneliti menemukan hasil bahwa subjek $\mathrm{CH} \& \mathrm{ARN}$ mampu untuk menerapkannya, sedangkan subjek NKP \& AFH mereka menyatakan setuju menerapkan aspek ini namun dalam penerapannya mereka berdua masih tidak maksimal karena jika dalam keadaan bercanda atau berguyon mereka berdua tidak menerapkannya. Yang terakhir, aspek qaulan baligha untuk aspek ini subjek $\mathrm{CH}, \mathrm{NKP}, \mathrm{AFH}$, dan ARN semuanya memiliki kesamaan, menerapkannnya.

Faktor-faktor yang mempengaruhi subjek untuk menerapkan aspek-aspek komunikasi interpersonal dalam kajian Islam dalam penelitian ini sangat beragam, namun dari hasil penjabaran data penelitian dan pemabahasan maka peneliti melihat bahwa dari beberapa faktor yang sudah dijabarkan sebelumnya, faktor yang paling banyak mempengaruhi adalah faktor yang datang dari luar diri subjek yaitu lingkungan sekitar subjek yang membiasakan subjek menerapkan aspek-aspek tersebut, selain itu juga subjek- 
subjek penelitian merasa ketika menerapkan beberapa aspek mereka bisa mendapatkan atau merasakan rasa senang dalam diri mereka masing-masing.

Saran

Berdasarkan pemaparan dari hasil penelitian yang telah dilakukan, peneliti memberikan beberapa saran untuk pihak yang terkait diantaranya adalah saran yang ditunjukkan kepada subjek penelitian dan untuk peneliti selanjutnya yaitu, bagi subjek penting untuk diperhatikan ketika sedang siaran bersama dengan pasangan siaran ajang duet maupun dalam kehidupan sehari-hari, karena pekerjaan yang menonjolkan sisi di bidang komunikasi dan merupakan seorang muslim/muslimah maka subjek bisa mencoba melatih untuk menerapkan setiap aspek dari komunikasi interpersonal dalam kajian Islam ini agar bisa terbiasa. Lalu bagi peneliti selanjutnya yang memiliki keinginan untuk melakukan penelitian terkait tema komunikasi interpersonal dalam kajian Islam agar dapat memperbanyak subjek penelitian atau menambahkan konsep-konsep dari psikologi islam lainnya sehingga hasil penelitian yang didapatkan lebih beragam. Selain itu, bisa saja penelitian dilakukan untuk posisi pekerjaan yang lain dan tidak lupa penting bagi peneliti untuk bisa membangun hubungan yang baik dengan subjek maupun pihak-pihak lainnya yang terkait dalam penelitian agar dapat memudahkan peneliti dalam proses pengambilan data.

\section{Referensi}

Al-Qur'an. (2010). Al-Qur'an, Terjemah, dan Tafsir untuk Wanita. Bandung: Penerbit JABAL.

dBsFM, M. R. (2020, Juni 28). Wawancara pribadi, Via Whatsapp. (Y. Syifa, Interviewer)

Jalaluddin Rakhmat. Islam Aktual. Bandung: PT. Mizan Pustaka, 2021.

Mubarok dan Made Dwi Andjani. Komunikasi Antarpribadi Dalam Masyarakat Majemuk. Dapur Buku, 2014.

Muslimah. Etika Komunikasi Dalam Persfektif Islam. Jurnal STAI An-Nadwah Kuala Tungkal, Volume 13, 2016.

Na'imah, Tri, dan Dyah Siti Septiningsih. Komunikasi Interpersonal Dalam Kajian Islam, Prosiding Seminar Nasional Universitas Muhammadiyah Purwokerto, 2019.

Semiawan. Metode Penelitian Kualitatif (Jenis, karakteristik dan Keunggulannya). Jakarta: PT Grasindo, 2010. 
Sugiyono. Metode Penelitian Kualitatif (Untuk Penelitian yang Bersifat: Eksploratif, Enterpretif, Interaktif, dan Konstruktif). Bandung: Alfabeta, 2020.

Riady, Yasir, dan M Hum. Mewujudkan Masyarakat Informasi Indonesia Dampak Sosial, Konsekuensi dan Kemungkinannya. Prosiding Seminar Nasional Universitas Terbuka Banjarmasin, 2010.

Syaiful Djamarah. Pola Asuh Orang Tua dan Komunikasi dalam Keluarga. Jakarta: PT. Asdi Mahasatya, 2020.

Triartanto A.Ius.Y. Broadcasting Radio: Panduan Teori dan Praktek. Yogyakarta: Pustaka Book, 2010.

Trinoviana, Anindita. 2017. Strategi Konvergensi Radio Sebagai Upaya Perluasan Pasar Audience dan Iklan (Studi Kasus Pada Swaragama Fm (101.7 Fm), Geronimo Fm (106.1 Fm), Dan Prambors Radio (102.2 FM/95.8 FM)). Jurnal Komunikasi, Volume 12, No. 1, 2017.

Wanda Yulia. Andai Aku Jadi Penyiar. Yogyakarta: Andi, 2010.

Y. Bambang Triyono. Pengetahuan Dasar Presenter Radio Dan Televisi. Artikel http://puslitbangdiklat.rri.co.id/, 2017.

\begin{tabular}{|c|c|c|c|c|}
\hline Submit & Review & Revisi & Diterima & Publis \\
\hline $25-10-2021$ & $\begin{array}{l}24-11-2021 \text { sd } 01-12- \\
2021\end{array}$ & 04-01-2022 & 08-01-2022 & 04-02-2022 \\
\hline
\end{tabular}

Nor Yulia Syifa, Shanty Komalasari, dan Musfichin

Program Studi Psikologi Islam

Fakultas Ushuluddin dan Humaniora

Universitas Islam Negeri Antasari Banjarmasin

Email: yuliasyifa99@gmail.com 